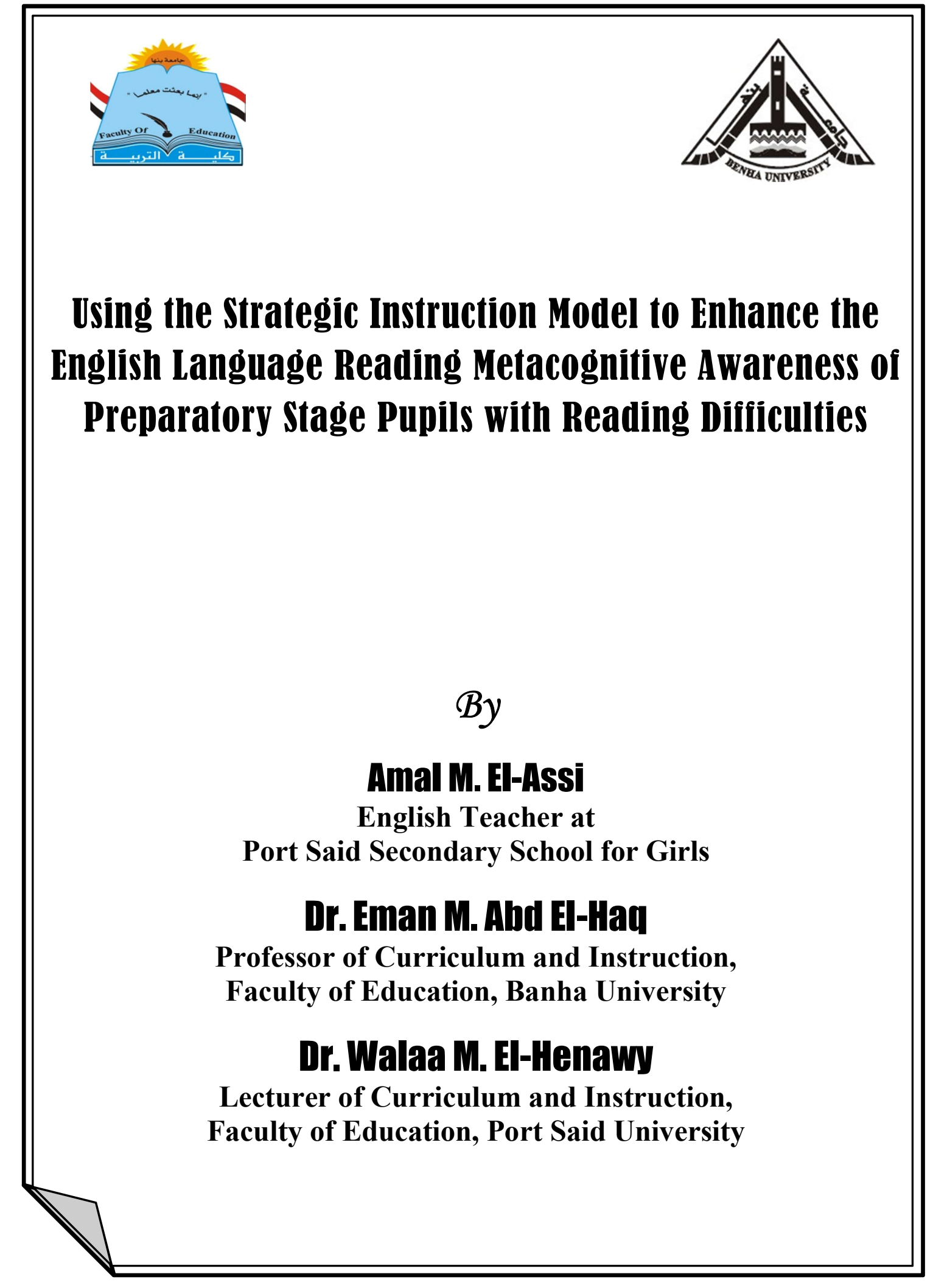




\title{
Using the Strategic Instruction Model to Enhance the English Language Reading Metacognitive Awareness of Preparatory Stage Pupils with Reading Difficulties
}

By

\author{
Amal M. El-Assi
}

English Teacher at

Port Said Secondary School for Girls

Dr. Eman M. Abd El-Haq

Professor of Curriculum and Instruction, Faculty of Education, Banha University

Dr. Walaa M. El-Henawy

Lecturer of Curriculum and Instruction, Faculty of Education, Port Said University

\section{Ahstract}

The purpose of this study was to investigate the effectiveness of using the reading strategies of the Strategic Instruction Model (SIM) to enhance the reading metacognitive awareness of the second-year preparatory stage pupils with reading difficulties. Twenty-four female pupils at Al-qanaa Preparatory School for Girls participated in this study using the one-treatment design. An intelligence test, a diagnostic reading comprehension test, a questionnaire of the behavioral characteristics of the pupils, and a metacognitive awareness scale were conducted for collecting data. Descriptive statistics were used for data analysis. Findings demonstrated that the reading strategies of the Strategic Instructional Model were effective in enhancing reading metacognitive awareness of the second-year preparatory stage pupils with reading difficulties. 


\section{Introduction}

It is indisputable that reading is the core of most proficient academic practices. Therefore, having efficient reading metacognitive awareness is the pupil's gate to achieve sound academic success and to acquire other language skills. However, reading is not a simple skill to be mastered as it is one of the most complex skills that entails coordination between numerous complex processes which are required for an optimal reading practice.

Hence, Reading comprehension difficulties are tightly related to the lack of metacognitive awareness as struggling readers might not realize the mental effort that goes into constructing meaning. Those readers might look at achieving readers as they breeze their way through the text and that comprehension is something that takes place automatically for them. Struggling readers need to know that constructing meaning takes effort, but that effort pays off (Gunning, 2010, p. 375). Accordingly, Reid and Lienemann (2006, p.25) assert that students with learning difficulties are not involved in the learning tasks due in large part to a problem with metacognition.

Therefore, effective metacognitive awareness enables the readers to monitor their comprehension and know when they are construction meaning and when they are not. When comprehension breaks down due to lack of background information, difficulty or words, or unfamiliar text structure, readers with good metacognitive awareness know a variety of fix-up strategies to use. These include rereading, changing the pace of reading, using context clues, cross-checking cueing systems and asking for help. (Mclaughlin and Allen, 2001, p. 10).

Consequently, it is a must for pupils with reading comprehension difficulties to face these difficulties by obtaining mental tools, tricks, or shortcuts to gaining meaning, understanding, or knowledge. Therefore, the proper instruction of multiple, efficient and well-developed reading comprehension strategies can enhance and enlarge the scope of their learning by making it more efficient. (McEwan, 2001, p. 44). 
Therefore, there must be a comprehensive approach to adolescent literacy that addresses the need of students to be able to read and understand large volumes of complex materials (Strategic Instruction Model Guide, 2011, p. 4). According to Schumaker and Deshler (2006, p. 150), developing the strategic Instruction Model for adolescents with learning difficulties was due to that data convincingly show that at risk adolescents, including those with difficulties, are markedly behind their peers because they lack the necessary skills and strategies to successfully negotiate the demanding environment of a preparatory and secondary schools. Therefore, Schumaker and Deshler (2006, p. 151) have developed a set of learning strategy interventions that now comprise the Learning Strategies Curriculum of the Strategic Instructional Model. These strategies are designed to enable students to learn how to acquire information from written materials, store that information in some way, and express that information on a test, in an assignment, or in a written paper.

\subsection{Background}

There is also a positive cause and effect relationship between metacognitive awareness and achievement of students, whether in terms of academic achievement or language proficiency. Kummin and Rahman (2010, p. 146) conclude that there is a strong relationship between metacognition and students' achievement, which reflects the importance of the role of metacognition in the learning process as it is an essential ingredient to develop learners to be effective readers, a key factor for proficient strategic reading and an element necessary for many cognitive learning tasks.

Therefore, with solid metacognitive reading awareness, learners are aware of their goals. In addition, they are able to monitor the reading process, check their reading comprehension, arrange strategies, evaluate their strategy application and after evaluation, adjust their choice of strategy if needed. Learners are empowered with metacognition through the effective monitoring of the comprehension processes, which were considered important in developing skilled reading (Maasum and Maarof, 2012, p. 1253). 
However, In spite of the importance of metacognitive awareness, it has long been the ignored skill in English language teaching, research, learning, and assessment. This lack of good metacognitive reading skills is exacerbated by the central role of reading comprehension in education success (Ahmadi, Ismail and Abdullah, 2013, p. 235). Hence, this study introduces several reading strategies that are based on strategic direct instruction approach which is closely related to the area of metacognition.

\subsection{Context of the Problem}

Based upon reviewing literature, there is a lack of research-based classroom reading practices during different educational stages, especially those address the educational needs of pupils with reading difficulties as proven by a number of studies suggesting more work and research in this field (Ali, 2014; Attia, 2013; Al-Neguly, 2013; Eid, 2008; El-Morsi, 2007; Yasin, 2002). In addition, according to the researcher's knowledge, there is a lack of studies that used specialized models in dealing with learning difficulties, in general, and reading difficulties, in particular. Furthermore, the literature related to reading metacognitive awareness highlighted the link between poor metacognitive awareness and poor academic achievement in general and reading comprehension difficulties in particular which was supported by a number of studies. Among them are: Khalil, 2012; Abdul Salam, 2012; Zaza, 2001; Ghanem, 2001; and Abou-Hadid, 2011. This study seeks to add to the research literature of EFL reading instruction by examining the effectiveness of the strategic instructional model in enhancing the reading comprehension and metacognitive awareness of the second-year preparatory stage pupils with reading difficulties.

Evidence provided by reviewing the literature was supported by conducting a pilot study by the researcher by the end of October 2013. A pilot study that included a brief reading metacognitive awareness scale aimed at examining the reading metacognitive awareness of the second- 
year preparatory stage pupils. It was administered to 47 pupils at Port Said Preparatory School for Girls, 50 pupils at Al-malik Faisal Preparatory School for Girls, and 7 pupils at Al-diba Co-educational Preparatory School. Surprisingly, $90 \%$ of the pupils scored high on the scale which dramatically contradicted with their results on their reading school achievement tests. However, a number of studies (e.g. Guthrie and Wigfield, 2000 and Pressley, 2000) illustrate that pupils with low reading metacognitive awareness have misconceptions about themselves. Therefore, it is extremely hard for them to recognize their reading difficulties. This misconception makes their problems even more serious.

In conclusion, those students has been proven to have low reading metacognitive awareness because of the high inconsistency between the results of their reading achievement tests and their scores on the presented reading metacognitive awareness scale.

\subsection{Statement of the Problem and Research Questions:}

Based on the previous studies, the problem of the present study can be identified in the second-year preparatory stage pupils' inefficient reading metacognitive awareness. Therefore, the present study is an attempt to investigate the effectiveness of the reading strategies of the Strategic Instructional Model in enhancing the reading metacognitive awareness of the second-year preparatory stage pupils with reading difficulties through investigating the following questions:

1- To what extent do the second-year preparatory stage pupils with reading difficulties demonstrate the required reading metacognitive awareness skills?

2- How effective are the reading strategies of the strategic instructional model in enhancing the reading metacognitive awareness of second-year preparatory stage pupils with reading difficulties? 


\section{Review of Literature:}

\section{Reading Metacognitive Awareness:}

There are two interrelated concepts that lead to different theories and approaches about how reading comprehension should be taught or learned and also resulted in the development of many reading strategies that are taught explicitly or implicitly. The two correlated concepts are: cognition and metacognition. It is important to differentiate between the two concepts: cognition and metacognition. Reid (2005, p. 10) defines cognition as the actual processes involved in learning a piece of information. This relates to memory, understanding, organizing and generally making sense of information, while metacognition refers to awareness of and conscious control over those skills. It is the person's awareness and understanding of that knowledge.

According to Luke (2006, p. 2), metacognitive awareness, simply, is the learner's awareness of the learning process, and what it takes to achieve good results in a specific learning task. Gersten, et al. (2001, p. 281) also present a definition of the metacognitive ability that coincides with the previously- mentioned definition. They define it as the ability to manage and control one's cognitive activities and evaluate whether or not they are performing successfully.

Various reading strategies exist under the umbrella of metacognitive awareness. Therefore, Gilani, Ismail and Gilakjani (2012, p. 77) offered a definition of metacognitive strategies as administrative actions taken in reading which include planning for learning, thinking about the process of learning, self-management, self-monitoring, directed attention, observing, correcting of one's comprehension or production, direct attention and evaluating at the different learning phases, for example, before, during, and after learning.

A number of studies have asserted the importance of metacognitive awareness. For instance, Mehrdad, Ahghar and Ahghar (2012) conducted a study as an attempt to find out whether teaching "cognitive and metacognitive strategies" affects EFL students' reading 
comprehension across proficiency levels. The subjects of this study were one hundred and eighty B.A. students majoring in English from Azad University. The results revealed that teaching such strategies had significant effects on the reading comprehension of EFL students.

Zoghi, Mustapha and Maasum (2010) carried out another study to explore the degree of EFL learners' awareness of reading comprehension strategies and their potential comprehension failure. To this end, $12 \mathrm{EFL}$ university-level students were interviewed. An analysis of student interview data revealed that there is an instructional void as regards to reading strategy training in the educational settings.

Another study was conducted by Temur, et al. (2010) to investigate the differences among 6th, 7th, and 8th grades in respect to their metacognitive awareness in the field of reading. The result of the study revealed that there was a positive correlation between grade level and metacognitive awareness in reading, but the difference was not statistically significant.

McTavish (2008) conducted a qualitative case study in which McTavish illustrates and compares the metacognitive strategies that a grade-3 female student used while reading narrative and informational texts. Findings showed that the subject used markedly different metacognitive strategies for each genre, resulting in comprehension difficulties while reading the informational text. The study reflected the value of empowering the learner's with the skill of selecting the right action to be taken while dealing with various reading genres.

One of the significant studies that assert the importance of metacognitive awareness for students with learning difficulties is Trainin and Swanson's (2005) study which considered whether successful students with learning difficulties rely on metacognitive awareness to compensate for processing difficulties. The study compared the cognitive and metacognitive performance of students with and without learning difficulties $(\mathrm{N}=40)$. Results showed that students with LD compensated 
for their processing deficits by relying on verbal abilities, learning strategies, and help seeking.

Mokhtari and Reichard (2004) conducted another study to investigate whether significant differences exist between first and foreign language readers in their metacognitive awareness and perceived use of specific strategies when reading for academic purposes in English. Three hundred and fifty college students (141 US and 209 Moroccan) completed an instrument designed to measure their metacognitive awareness of reading strategies. The results revealed that the two student groups reported remarkably similar patterns of strategy awareness and usage when reading academic materials in English. Where differences were found, Moroccan students reported using certain types of strategies more often than did their American counterparts. The study confirmed the value of metacognitive awareness for both first and foreign language learners.

Concerning reading metacognitive awareness, Mokhtari and Reichard (2002, p. 253) define three broad categories of reading strategies that can be used to measure adolescent and adult students' awareness and use of reading strategies while reading academic or school-related materials. The three categories are:

(1) Global Reading Skills (GLOB), which can be thought of as generalized or global reading skills aimed at setting the stage for the reading act (e.g., setting a purpose for reading, previewing text content, predicting what the text is about, etc.),

(2) Problem-Solving Skills (PROB), which are localized, focused problem-solving or repair skills used when problems develop in understanding textual information (e.g., checking one's understanding upon encountering conflicting information, re-reading for better understanding, etc.), and

(3) Support Reading Skills (SUP), which involves using the support mechanisms or tools aimed at sustaining responsiveness to reading (e.g., use of reference materials like dictionaries and other support systems). 
Mokhtari and Reichard's categorization is adopted by the current study as it is highly linked to metacognitive reading awareness not metacognition in general; and more relevant than the wide divisions of planning, monitoring, and evaluation.

To conclude, enhancing reading metacognitive awareness for students with reading difficulty is, however difficult, is possible and necessary process that can lead to significant improvement in the whole reading practice. More than any other student, the student with reading difficulty need a clear set of procedures, techniques, or strategies that can be mastered to help him understand his/ her reading problems.

\section{Reading Difficulties:}

The hallmark characteristic of a learning difficulty is an individual's academic underachievement in reading, writing, and/or mathematics despite the presence of average to above average intelligence, appropriate instruction, regular school attendance, and favorable environmental factors. (Saskatchewan, 2004, p. 10).

Spear-Swerling (2004, p. 518) provides a definition of reading difficulty as an "unexpected" reading failure that cannot be accounted for by other difficulties, generalized cognitive-linguistic weaknesses, or obvious environmental causes, including a lack of appropriate instruction. There is a consensus between researchers (Perfetti, Linda, and Oakhill , 2005, p. 140; Gajria, et al. , 2007, p. 211; Gersten, et al., 2001, p. 280) that reading difficulty occurs to students with average or above average intelligence studying under normal conditions which is a solid ground the current study uses to base sample selection. Furthermore, defining the aspect of weakness (word-recognition, reading comprehension, or both) is also critical as it can make the process of diagnosis and intervention much easier.

Perfetti, Linda, and Oakhill (2005, p. 140) define readingcomprehension difficulty simply as that a shown deficit in reading comprehension that is markedly discrepant with reading accuracy. In 
addition, Gajria, et al. (2007, p. 211) define students with reading comprehension difficulties as students who either lack or fail to activate reading comprehension strategies to access information in textual material and, typically, do not monitor and evaluate their understanding of text. This previous definition of students with reading difficulties sheds light on the value of teaching students reading comprehension strategies.

Traditionally, a discrepancy model has been used to make the diagnosis of a learning difficulty. The discrepancy is based on results from intelligence and academic achievement tests. An analysis is made of the discrepancy between the student's obtained scores on the intelligence and achievement tests. The essence of the discrepancy model is that the academic achievement performance falls well below expectations based on intelligence. If a significant discrepancy is found, then a diagnosis of a learning disability is made (Saskatchewan, 2004, pp. 15-16).

A number of studies have been conducted to investigate the nature of EFL reading comprehension difficulties. One of the these studies was conducted by Said (2012) which aimed at investigating the effectiveness of a decoding-based program in overcoming some EFL reading problems among primary school pupils. The sample of the present study consisted of sixth year primary stage at El Wehda -Primary School -ZeftaGarbeya Governorate. Results of the study revealed that some of EFL reading problems were overcome as a result of teaching through the program.

Another study was carried out by Mesalhy (2009) to investigate the effectiveness of using a suggested program based on schemata strategy in treating some EFL reading difficulties among second year prep stage students. The subjects of this study included (40) second year prep stage student at Omar Ibn Abdel Aziz Prep School. A Treating Reading Difficulties Program (TRDP) was designed to treat some EFL reading difficulties which second year prep stage students face during reading. Results indicated that the suggested program was effective in treating some EFL reading difficulties among prep stage students. 


\section{Strategic Instruction Model}

Bryant et al. (1999, p.295) state that students with reading difficulties in middle and high school grades need assistance in reading to be able to integrate new information with their prior knowledge, to obtain important information from the text, and to remember what they have read. Thus, reading instruction is an important component of all secondary curricula and includes strategy instruction in word identification, vocabulary, and comprehension skills.

According to Peterson, et al. (2000, p. 61), the Strategic Instruction Model (SIM) is a system of teacher instructional routines (called Content Enhancement) and student learning strategies (called the Learning Strategies Curriculum). Deshler et al (2001, Cited in Swanson \& Deshler, 2003, p.p. 129-130) illustrate that the Content Enhancement is an approach to planning instruction for and teaching content to diverse groups of students in the general education classroom. It involves making decisions about what content to teach, manipulating and translating that content into easy-to-understand formats, and presenting it in memorable ways. The routines are sets of inclusive teaching practices that help teachers carefully organize and present critical information in such a way that students identify, organize, comprehend, and recall.

According to Luke (2006, p. 4) the Learning Strategies Curriculum of SIM is a series of interconnected, student-centered strategies designed to transform weak or passive learners into students who know how to learn and apply their knowledge and skills actively across various learning environments. Learning Strategies are designed to help students understand information and solve problems. Learning Strategy instruction focuses on making students more active learners by teaching them how to learn and how to use what they have learned to be successful. Both Content Enhancement and Learning Strategies have been successfully field tested with students judged to be at risk for academic. 
Luke (2006, p. 3) also identifies seven discrete strands and more than 30 strategies of SIM that can improve skills and performance related to:

1- Reading

2- Expressive Writing

3- Math and Problem Solving

4- Studying and Remembering

5- Assignments and Test Taking

6- Motivation

7- Interacting with Others

Peterson, et al. (2000, p. 61) clear up four reading strategies, which can be implemented separately:

1- The Word Identification Strategy helps students decode unknown words while reading of content-area texts. The strategy teaches students to predict meaning from context and to use word analysis.

2- The Paraphrasing Strategy teaches students to read a limited section of material, to determine main idea and details, and to express the meaning in their own words.

3- The Self-Questioning Strategy teaches students to construct questions about key pieces of information in a passage and then to read for answers.

4- The Visual Imagery Strategy teaches students to visualize the scene that is described, incorporating actors, action, and details. They learn and practice in short passages. The strategy is designed to improve their learning and recall of prose material.

Furthermore, two more reading-related strategies are added to the Strategic Instruction Model which are:

1- Inference Strategy that helps students to answer inferential questions 
2- The Fundamentals of Paraphrasing and Summarizing that is designed to teach the fundamental skills students need to be able to identify and paraphrase main ideas and details (Learning Strategies Guide, 2009, p.p. 1-2). The strategies that are examined in the current study are The Paraphrasing Strategy, The Visual Imagery Strategy, The Self-Questioning Strategy, and The Inference Strategy.

According to Watson, et al. (2012, p. 84), Lenz (2006, p. 72), Hagaman and Reid (2008, p. 223) and Lebzelter and Nowacek (1999, p. 213), the paraphrasing strategy (RAP) is made up of three steps:

1- read a paragraph;

2- ask yourself what is the main idea and what are important supporting details;

3- put the main idea and supporting details into your own words.

Watson, et al. (2012, p. 84) indicate that the RAP strategy requires students to monitor their comprehension by asking themselves after each paragraph, "What are the main idea and details of this paragraph?" Students are taught to find the main idea of a paragraph by looking at the first sentence of the paragraph and asking themselves, "Does this sentence tell what the paragraph is about?" If the first sentence of the paragraph is not the main idea, students look for repetition of words in the paragraph. Once they learn to find the main idea, students learn to find the details by asking themselves, "What information in this paragraph tells me more about the main idea?"

Schumaker, Deshler, Zemitzsch, \& Warner (1993, p. 46) number five steps of the visual imagery strategy. Mnemonic SCENE is used to remind students of the steps of the visual imagery strategies. The steps are:

1 - Search for picture words.

2- Create or change the scene.

3- Enter lots of "details."

4- Name the parts.

5- Evaluate your picture. 
Lenz (2006, p. 73) and Berkeley, Marshak, Mastropieri, and Scruggs (2011, p. 107) identify three steps of the Self-Questioning Strategy. Students can remember the steps using the mnemonic ASK-IT:

1 - attend to clues as you read;

2- say some questions;

3- keep predictions in mind;

4- identify the answer;

5- talk about the answers.

According to, Fritschmann, Deshler and Schumaker (2007, p. 248), the inference strategy taught to the students in this study consists of five steps:

1- Interact with the passage and the questions

2- Note what you know

3- Find the clues

4- Explore more details

5- Return to the question

These strategies are initially designed to be used separately. However, Lencioni's study (2013) integrated the use of several reading comprehension strategies. It investigated the effects of explicit direct instruction and cooperative learning on reading comprehension of 105 fourth grade students. A quasi-experimental design was used. The students were taught the reading strategies of generating questions, making connections, summarizing, vocabulary building, and visualizing through explicit direct instruction. These strategies were practiced either independently or in cooperative learning groups. It was concluded that lower performing readers benefit from explicit direct instruction with independent practice of reading comprehension strategies.

However, the most important study on the integration of SIM reading strategy was conducted by Schumaker, et al. (2006). The researchers reported a reading comprehension course that was developed and tested for students who earn reading comprehension scores that are 
substantially below grade level. In this semester-long course, students who have already mastered the Word Identification Strategy or who are already decoding fluently are taught a series of reading comprehension strategies, including the Visual Imagery Strategy, the Self-Questioning Strategy, the Paraphrasing Strategy, and the LINCS Vocabulary Strategy. The positive results of the study reflected the effectiveness of reading comprehension strategy integration.

To conclude, the Strategic Instruction Model (SIM) for reading instruction is a well-researched model that aim at improving decoding, reading comprehension, and the metacognitive awareness of students with learning disabilities and difficulties. The most significant characteristic is that SIM is that it is designed specifically for students with difficulties and disabilities. Another characteristic is that it has detailed instructional stages that can assist the teachers and researchers to follow a step- by- step process that can enable the student to be aware and responsible for his/ her reading experience. The reading strategies are designed basically to be applied separately. However, the integration of these strategies is possible and beneficial as proven by a number of studies such as Lencioni (2013), Schumaker, et al (2006) and Clark, et al. (1984).

\section{Methodology:}

\subsection{The Participants of the study:}

This study targeted preparatory stage pupils with reading difficulties. Hence, there was a preliminary diagnosing process to identify the sample of the study. Ninety seven female pupils from preparatory stage of Al-Qanaa Preparatory school for girls at Port Said city of the academic year 2014/2015 underwent the following tests

1- Test of Mental Ability (12-14 years) (Moussa, 1984) to assess the pupil's intellectual functioning in order to exclude all the pupils who obtained a below-average intelligent scores. 
2- Diagnostic test, which was used to determine the pupils reading comprehension skill level.

Based on the results of the previous two tests and using the Reynolds' example of the discrepancy calculation between achievement and aptitude scores, a number of 28 female pupils were selected. Ensuing that a List of the Characteristics of Pupils with learning difficulties (AlSaid, 2010) was administered to confirm the results of the previous tests. After the application of the list, 4 other pupils were excluded as they did not show a minimum of six out of the ten characteristics defined by the list. The number of the pupils after the diagnosing process was 24 female pupils $(n=24)$. They had five periods per week. Each period lasted approximately 45 minutes. The experimental group was taught by the researcher using the reading strategies of the Strategic Instructional Model. Reading comprehension passages from the pupils' English textbook were used along with a number of other reading comprehension passages provided by the researcher.

Table 1 Characteristics of the Participants

\begin{tabular}{|c|c|c|c|c|}
\hline Sample & Grade & $\begin{array}{c}\text { Mean } \\
\text { of Age }\end{array}$ & Type of School & $\begin{array}{c}\text { Experience of } \\
\text { learning English as a } \\
\text { Foreign Language }\end{array}$ \\
\hline \hline Experimental & $\begin{array}{c}\text { The Second year } \\
\text { of preparatory } \\
\text { stage }\end{array}$ & $12-13$ & Governmental & 7 years \\
\hline
\end{tabular}

\subsection{Hypotheses of the Study:}

1- There is a statistically significant difference between the mean scores of the experimental group on the Pre and Post administration of the Reading Metacognitive Awareness Scale in favor of the post administration.

2- There is a statistically significant difference between the mean scores of the experimental group on the pre-post administration of the three subscales of reading metacognitive awareness scale: Global Reading, Problem-solving, and Support Reading in favor of the post administration. 


\subsection{Instruments of the Study:}

To fulfill the purpose of the study, the following instruments were used:

1- Test of Mental Ability (12-14 years) (Moussa, 1984)

2- List of the Characteristics of Pupils with learning difficulties (AlSaid, 2010)

3- Diagnostic Reading Comprehension Skills test (prepared by the researchers)

4- Reading Metacognitive Awareness Scale (Alhaqbani and Riazi, 2012).

\section{Test of Mental Ability (12-14 years) (Moussa, 1984):}

This test was designed to measure the general mental ability on the ground that the different factors that form that ability correlate with each other. It was used in the current study as part of the preliminary diagnosing stage of the sample of the study. The test contained 90 questions ascendingly ordered according to their level of difficulty. The researcher selected this test due to the accurate age specification as the test was designed for pupils in preparatory school (12-14 years) in addition to its high validity and reliability.

\section{Validity of the Test of Mental Ability}

Moussa (1984) calculated the following to determine the validity of the test:

1- Point Biserial Correlation Coefficient which was 0.80 .

2- The correlation between this test and the Pictured intelligence test and the Primary Mental Abilities Test was calculated which were 0.80 and. 0.88 respectively.

\section{Reliability of the Test of Mental Ability:}

Reliability of the test was estimated by calculating:

1- Alpha Cronbach Reliability Coefficient which was 0.905

2- Split- half Reliability Coefficient which was 0.950 . 
The List of the Characteristics of Pupils with learning difficulties (Al-Said, 2010)

The list was used in the current study to confirm the diagnosis that was based on the discrepancy between students' aptitude measured by the Mental Ability Test and students' achievement measured by the diagnostic test. It is generally used for fast screening procedures as it includes the most important and common characteristics of pupils with learning difficulties.

The list was divided into two sections. The first section included some basic data about the pupil, the evaluation result, some data about the evaluator, and the date of evaluation. The second section included the list of ten items that describe the behavioral characteristics evaluated by the pupil's teacher or the parent. It is preferable to be the teacher that spent at least three months teaching for the pupil to be able to provide more accurate and valid evaluation of the child. It is not necessary that the pupil shows the all the ten characteristics as only a minimum of six is required for a preliminary diagnosis of a learning difficulty.

\section{Validity and Reliability of the List}

The researcher selected this list due to its high validity and reliability as the list was reviewed by 20 learning difficulty specialists and the agreement among the specialist on all the characteristics was from $92 \%$ to $98 \%$. The Split half reliability coefficient was 0.94 and Alpha Cronbach reliability coefficient was 0.9.

\section{Diagnostic Reading Comprehension Skills test (prepared by the researcher)}

The final version of the test was modified according to the feedback provided by the jury members. The diagnostic skill test consists of 3 reading passages. The first passage entitled Rain, the title of the second is Fit for Life, and the third is Middle East Rally Championship. Each passage was followed by 6 questions: three literal, one inferential, two evaluative. The questions of the test included both (7) multiple choice questions, (5) single-word response questions and (6) short- 
response questions. The total number of the questions in the test was 18 questions. The three passages of the test were intended to assess the (18) selected reading comprehension skills which were distributed over the whole test as shown in table.

\section{Validity of the Test:}

In order to achieve the validity of the test, it was submitted to a jury of specialists in curricula and methods of teaching English $(n=9)$. They were requested to read the passages and the questions and give their opinion concerning:

1- The suitability of content.

2- The difficulty and length of the passages.

3- How far each question measure the skills intended to measure

All the comments of the jury were thoroughly considered such as omitting two questions as the skills they were testing did not suit pupils' levels, clarifying the accompanying pictures, and rephrasing few questions to be clearer to the pupils. After the required modification, the test was valid as it was approved by the jury. The final form of the test.

The test was administered to a pilot sample of 27 second year preparatory stage pupils at Port Said Preparatory School for Girls for the sake of:

1- making sure that the questions were understood by the pupils

2- setting the time limit of completing all the items of the test.

The pupils were not included in the control group of the study. Time was determined by calculating the mean time in which the fastest pupil and the lowest one took in answering the test. It was estimated that 90 minutes would be the appropriate time needed for answering all the given items.

Concerning the score of the test, it was estimated as follows:

Two points for each multiple choice question.

Two point for each single-word response questions.

From zero to five points for each written short answer 


\section{The Reliability of the Pre-diagnostic Test:}

To measure the reliability of the test, the results of the pilot administration were used. It was assessed through calculating the internal consistency of the test by using Cronbach's Alpha formula. The reliability of the test was verified by 0.74 reliability coefficient.

\section{Reading metacognitive awareness scale}

The metacognitive awareness scale is designed by Mokhtari \& Reichard (2002). It was used in the current study to investigate the effectiveness of using the strategic instruction model in enhancing the metacognitive reading awareness of preparatory stage students with reading difficulties. An Arabic version of the scale developed by Alhaqbani \& Riazi (2010) was used in this study. Both the original and the translated version were administered to assess the reading metacognitive awareness of college students. Therefore, the reliability and validity of the test for preparatory stage pupils were assessed. The scale is made up of 30 items based on the categorization of three basic metacognitive reading:

(1) 13 Global Reading Skills (GLOB), which can be thought of as generalized or global reading skills aimed at setting the stage for the reading act (e.g., setting a purpose for reading, previewing text content, predicting what the text is about, etc.),

(2) 8 Problem-Solving Skills (PROB), which are localized, focused problem-solving or repair skills used when problems develop in understanding textual information (e.g., checking one's understanding upon encountering conflicting information, re-reading for better understanding, etc.), and

(3) 9 Support Reading Skills (SUP), which involves using the support mechanisms or tools aimed at sustaining responsiveness to reading (e.g., use of reference materials like dictionaries and other support systems). 
After reading each statement, pupils are asked to circle the number $(1,2,3,4$, or 5$)$ that applies to him/her using the scale. Each pupil's average is calculated using the met a cognitive awareness scoring rubric.

The scale was administered to a pilot sample of 30 pupils of the prep stage at Port Said preparatory school for girls for the sake of:

1- Making sure that the scale items were understood by the pupils

2- Setting the time limit of answering all the scale items.

Time was determined by calculating the mean time in which the fastest pupil and the lowest one took in answering the scale. It was estimated that 15 minutes would be the appropriate time needed for answering all the given items.

\section{Validity and Reliability of the Reading Metacognitive Awareness Scale}

To measure the validity of the scale, the scale was submitted to a panel of jury $(n=9)$ to assess the clarity of its items and instructions, and its suitability to measure metacognitive awareness of prep stage pupils with reading difficulties. All the comments of the jury were taken into consideration such as modifying some items to make the statements clearer for prep stage pupils. After implementing the required modifications, the scale was valid. Using the results of the pilot administration, the reliability was obtained through calculating the internal consistency by using Cronbach's Alpha formula. The reliability of the scale was verified by 0.865 reliability coefficient.

\subsection{Treatment:}

First, after the Test of Mental Ability (12-14 years) (Moussa, 1984) was administered to 97 pupils at the second year of preparatory stage, it was corrected and all the results below the average of 90 were excluded. Therefore, 32 out of the 97 pupils were not included. Afterwards, the diagnostic reading comprehension skill test was administered to the remaining 65 pupils. 
Table (2) the diagnostic reading comprehension skill test mean and standard deviation before discrepancy calculations.

\begin{tabular}{|c|c|c|c|c|}
\hline Skills & Assessment & Mean & N & SD \\
\hline \hline $\begin{array}{c}\text { Reading } \\
\text { Comprehension }\end{array}$ & Pre-assessment & 33.91 & 65 & 14.116 \\
\hline
\end{tabular}

Then, the results of the diagnostic reading comprehension skill test were compared to the Test of Mental Ability (12-14 years) (Moussa, 1984) using the Reynolds' example of the discrepancy calculation in which both test scores were standardized by converting them to z-scores. A z-score expresses a test score in standard deviation units using the following formula:

$$
z_{x}=(x-\bar{x}) / \sigma_{x} \text { In this formula: }
$$

$\boldsymbol{x}=$ the pupil's score on the test

$$
\bar{x}=\text { the test mean } \sigma_{x=\text { the test standard deviation }}
$$

If a pupil's score on the Test of Mental Ability (12-14 years) test was at least two standard deviations higher than his or her scores on the diagnostic reading comprehension skill test, the pupil was described as having a significant discrepancy between IQ and achievement. The score of 28 pupils on the Test of Mental Ability (12-14 years) were two standard deviations higher than his or her scores on the diagnostic reading comprehension skill test (see table 3 ) 
Table 3 Discrepancy between Test of Mental Ability (12-14 years) and diagnostic reading comprehension skill test

\begin{tabular}{|c|c|c|c|}
\hline Student Number & IQ Z-Score & $\begin{array}{c}\text { Pre- } \\
\text { Diagnostic } \\
\text { Test Z-Score }\end{array}$ & $\begin{array}{c}\text { Discrepancy between IQ } \\
\text { Z-Score and Pre- } \\
\text { Diagnostic Test Z-Score }\end{array}$ \\
\hline 1 & .94 & -1.34 & 2.28 \\
\hline 2 & .88 & -1.41 & 2.29 \\
\hline 3 & 1.00 & -1.13 & 2.13 \\
\hline 4 & .94 & -1.13 & 2.06 \\
\hline 5 & 1.06 & -.99 & 2.05 \\
\hline 6 & 1.13 & -1.13 & 2.25 \\
\hline 7 & 1.19 & -1.20 & 2.39 \\
\hline 8 & 1.19 & -.99 & 2.17 \\
\hline 9 & 1.19 & -.99 & 2.17 \\
\hline 10 & 1.25 & -1.06 & 2.31 \\
\hline 11 & .94 & -1.13 & 2.06 \\
\hline 12 & 1.00 & -1.06 & 2.06 \\
\hline 13 & 1.06 & -1.06 & 2.12 \\
\hline 14 & 1.13 & -1.13 & 2.25 \\
\hline 15 & 1.13 & -1.06 & 2.18 \\
\hline 16 & 1.19 & -1.06 & 2.24 \\
\hline 17 & 1.06 & -1.13 & 2.19 \\
\hline 18 & 1.19 & -1.20 & 2.39 \\
\hline 19 & 1.19 & -1.06 & 2.24 \\
\hline 20 & 1.19 & -.99 & 2.17 \\
\hline 21 & 1.19 & -.91 & 2.10 \\
\hline 22 & 1.13 & -1.06 & 2.18 \\
\hline 23 & 1.13 & -1.13 & 2.25 \\
\hline 24 & 1.19 & -1.06 & 2.24 \\
\hline 25 & 1.19 & -1.06 & 2.24 \\
\hline 26 & 1.06 & -1.20 & 2.26 \\
\hline 27 & .63 & -1.13 & 2.75 \\
\hline 28 & 1.06 & -1.06 & 2.12 \\
\hline Total & 28 & 28 & 28 \\
\hline
\end{tabular}


However, the List of the Characteristics of Pupils with Learning Difficulties (Al-Said, 2010) was administered to ensure that the diagnosed sample show at least six out of the ten defined characteristics as the most common among pupils with learning difficulties. The English teachers of the pupils were the ones who responded to the list by circling one of the two options: (yes/ No). In the light of the teacher responses, four more pupils were excluded as they did not meet the eligible criteria of showing at least six out of ten characteristics.

The number of the pupils after the diagnosing process was 24 female pupils at the second year of the preparatory stage $(n=24)$ (See Table 4).

Table 4 the diagnostic reading comprehension skill test mean and standard deviation after discrepancy calculations.

\begin{tabular}{||c|c|c|c|c|c||}
\hline $\begin{array}{c}\text { the Pre-diagnostic reading } \\
\text { comprehension skill test }\end{array}$ & N. & Minimum & Maximum & Mean & $\begin{array}{c}\text { Std. } \\
\text { Deviation }\end{array}$ \\
\hline \hline $\begin{array}{c}\text { Diagnostic } \\
\text { Valid N (listwise) }\end{array}$ & 24 & 14 & 21 & 18.42 & 1.558 \\
\hline
\end{tabular}

After the instruments were validated by jurors and piloted to establish its reliability, the pre-instruments were administered. Afterwards, the four reading comprehension strategies of the strategic instruction model were applied to the experimental group. The application was divided into ten sessions spread over 20 days. Each session took two consecutive periods of 90 minutes. The pupils attended three sessions a week. In the first four sessions, the researcher introduced the concepts of reading skills, reading Comprehension, reading difficulties, reading strategies, and the Strategic Instruction Model (SIM), then the steps and remembering systems, the modelling and the applying of the four reading comprehension strategies. The researcher used the instructional stages of Strategic Instructional Model with its eight steps.

Afterwards, there were four session in each two strategies were combined to be used together to make the pupils elicit the strategy that suit the reading task and manipulate the steps to use exactly what they 
need from the two give strategies. Finally, there were two other sessions in which the pupils started to integrate the four strategies together by determining on the strategies and the steps they need. The application included a number of 24 short reading passages. Four of them were from the pupils' book, and the rest were prepared by the researcher. Concerning the teaching aids used by the researcher, a number of handouts, flashcards, modelling and evaluation worksheets were used every session.

\section{Results and Discussion}

Research Questions 1: To what extent do the second-year preparatory stage pupils with reading difficulties demonstrate the required reading metacognitive awareness skills?

Research Hypothesis 1: There is a statistically significant difference between the mean scores of the experimental group on the Pre and Post administration of the Reading Metacognitive Awareness Scale in favor of the post administration.

To verify if the first hypothesis is true or not, the means, standard deviation and the t-test were calculated.

Table (5) the t-value of the means of difference in the experimental scores on the pre-post administration of the reading metacognitive awareness scale.

\begin{tabular}{|c|c|c|c|c|c|c|c|}
\hline \multirow{3}{*}{$\begin{array}{c}\text { Reading } \\
\text { Meta- } \\
\text { cognitive } \\
\text { Awareness } \\
\text { Scale }\end{array}$} & $\begin{array}{c}\text { Experimental } \\
\text { Group }\end{array}$ & $\mathrm{N}$ & Mean & $\begin{array}{c}\text { Std. } \\
\text { Deviation }\end{array}$ & $\mathrm{T}$ Value & DF & $\begin{array}{l}\operatorname{Sig}(2- \\
\text { tailed }) \\
\end{array}$ \\
\hline & $\begin{array}{c}\text { Pre- } \\
\text { administration }\end{array}$ & 24 & & & \multirow[b]{2}{*}{14.018} & \multirow[b]{2}{*}{23} & \multirow[b]{2}{*}{0.01} \\
\hline & $\begin{array}{c}\text { Post- } \\
\text { administration }\end{array}$ & 24 & 80.2083 & 3.69517 & & & \\
\hline
\end{tabular}

Thus, table 5 indicates that the t-value is significant at 0.01 . This proved that there is statistically significant difference between the mean scores of the experimental group on the Pre and Post administration of the Reading Metacognitive Awareness Scale in favor of the post administration. Therefore, this hypothesis was satisfactory supported. 


\section{The Pre-Post Adminstration of the Reading Metacognitive Awareness Scale}

100

80

60

40

20

0

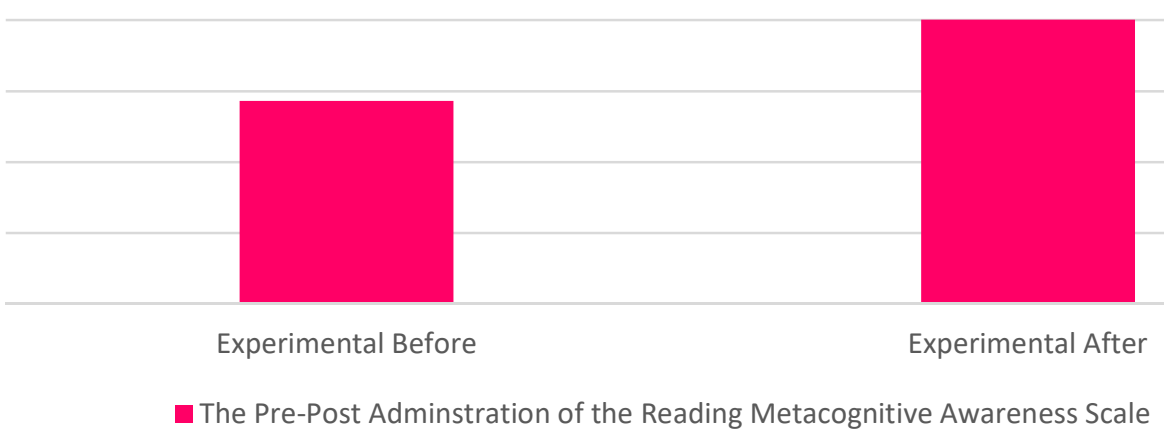

Figure (1): the means of the experimental scores on the pre-post administration of the reading metacognitive awareness scale.

Research Question 2: How effective are the reading strategies of the strategic instructional model in enhancing the reading metacognitive awareness of second-year preparatory stage pupils with reading difficulties?

Research Hypothesis 2: There is a statistically significant difference between the mean scores of the experimental group on the pre-post administration of the three subscales of reading metacognitive awareness scale: Global Reading, Problem-solving, and Support Reading in favor of the post administration.

To verify if the second hypothesis is true or not, the means, standard deviation and the t-test were calculated. 
Table (6) the t-value of the means of difference in the experimental scores on the three subscales of the pre-post administration of the reading metacognitive awareness scale.

\begin{tabular}{|c|c|c|c|c|c|c|c|}
\hline $\begin{array}{c}\text { Reading } \\
\text { Metacognitiv } \\
\text { e Awareness }\end{array}$ & $\begin{array}{c}\text { Experimental } \\
\text { Group }\end{array}$ & $\mathbf{N}$ & Mean & $\begin{array}{c}\text { Std. } \\
\text { Deviatio } \\
\mathbf{n}\end{array}$ & $\begin{array}{c}T \\
\text { value }\end{array}$ & DF & $\operatorname{Sig}(2$-tailed) \\
\hline \multirow{2}{*}{$\begin{array}{c}\text { Global } \\
\text { reading } \\
\text { strategies }\end{array}$} & Pre- & 24 & 19.7917 & 3.82190 & \multirow[b]{2}{*}{10.764} & \multirow[b]{2}{*}{23} & \multirow[b]{2}{*}{0.01} \\
\hline & Post & 24 & 29.2917 & 2.58238 & & & \\
\hline \multirow{2}{*}{$\begin{array}{l}\text { Problem- } \\
\text { solving } \\
\text { strategies }\end{array}$} & Pre- & 24 & 17.6250 & 3.21427 & \multirow{2}{*}{10.216} & \multirow{2}{*}{23} & \multirow{2}{*}{0.01} \\
\hline & Post & 24 & 24.4167 & 2.13802 & & & \\
\hline \multirow{2}{*}{$\begin{array}{c}\text { Support } \\
\text { reading } \\
\text { strategies }\end{array}$} & Pre- & 24 & 19.5000 & 2.02162 & \multirow{2}{*}{8.830} & \multirow{2}{*}{23} & \multirow{2}{*}{0.01} \\
\hline & Post & 24 & 26.3750 & 1.69268 & & & \\
\hline
\end{tabular}

Thus, table 6 indicates that the t-value is significant at 0.01 . This proved that there is a statistically significant difference between the mean scores of the experimental group on the pre-post administration of the three subscales of reading metacognitive awareness scale: Global Reading, Problem-solving, and Support Reading in favor of the post administration. Therefore, this hypothesis was satisfactory supported. 


\section{The Pre-Post Adminstration of the Metacognintive Awareness Subscales}

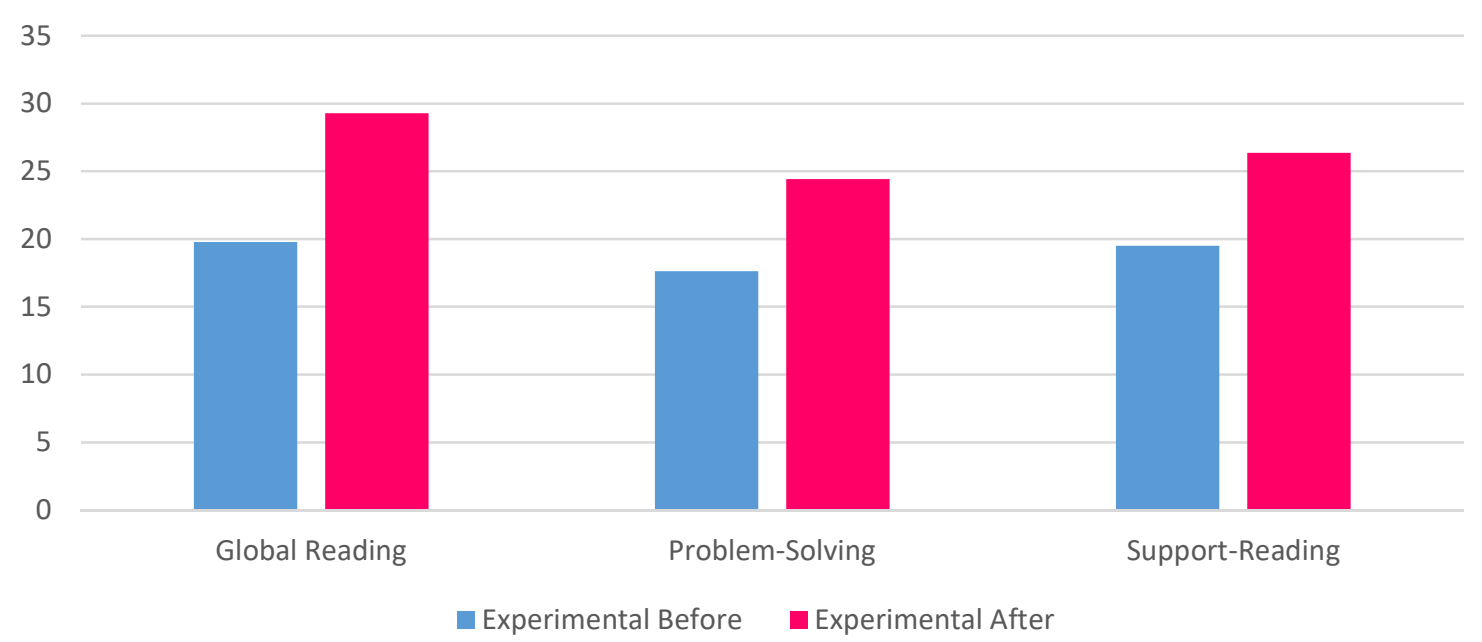

Figure (2): The Pre-post Administration of the Metacognitive Awareness Subscales

In sum, it can be concluded that the reading strategies of the strategic instructional model is effective in enhancing the metacognitive awareness of the preparatory stage pupils with reading difficulties.

\section{Conclusion:}

The present study attempted to enhance the reading metacognitive awareness of the second year preparatory stage pupils with reading difficulties through the use of four reading comprehension strategies (Paraphrasing, Self-questioning, Visual Imagery, and Inference) of the Strategic Instruction Model. The results of the current study proved the effectiveness of the reading strategies of the strategic instructional model in enhancing the reading metacognitive awareness of the second preparatory stage pupils with reading difficulties.

Therefore, Strategic Instruction Model is recommended for pupils with reading difficulties and low reading metacognitive awareness as pupils know exactly what they should do and how to handle complex reading texts. 


\section{References}

Abdul Salam, F. (2012). The metacognitive reading strategies used by skilled and poor readers of Arabic while reading in English. Unpublished master thesis, faculty of Arts, Helwan University.

Abou-Hadid, A. (2011). The effectiveness of the cognitive and metacognitive strategies on developing secondary school student's receptive skills. Unpublished master thesis, Faculty of Education, Ain Shams University.

Alhaqbani, A. \& Riazi, M. (2010).Metacognitive awareness of reading strategy use in Arabic as a second language. Reading in a Foreign Language, 24, (2), 231-255.

Ali, S. (2014). The effectiveness of using some multiple intelligences based activities in enhancing secondary school students' reading comprehension skills and attitudes towards reading. Unpublished master thesis, Faculty of Education, Mansoura University

Al-Neguly, W. (2013). Using project-based learning to develop EFL secondary stage students' writing and critical reading skills. Unpublished doctoral dissertation, Faculty of Education, Mansoura University.

Al-Said, A. (2010). Diagnosing learning difficulties: procedures and tools. Cairo: Dar Alfiker El-Arabi

Attia, M. (2013). The effectiveness of shared reading strategy in developing the primary stage pupils' early reading Skills. Unpublished master thesis, Faculty of Education, Mansoura University.

Berkeley, S., Marshak, L., Mastropieri, M., \& Scrugg, T. (2011). improving student comprehension of social studies text: a selfquestioning strategy for inclusive middle school classes. Remedial and Special Education, 32, 2,105-113. 
Bryant, R., Ugel, N., Thompson, S., \& Hamff, A. (1999). Instructional strategies for content-area reading instruction. Intervention in School and Clinic, 34, 5, 279-320. Retrieved in December 21, 2012, from isc.sagepub.com

Clark, F., Deshler, D., Schumaker, J., Alley, G., \& Warner, M. (1984). Visual imagery and self-questioning: strategies to improve comprehension of written material. Journal of Learning Disabilities, 17, 145-149.

Eid, S. (2008). The effectiveness of a proposed project-based internet program in developing some academic English reading and writing skills of post -graduates. Unpublished doctoral dissertation, Faculty of Education, Mansoura University

El-Morsi, H. (2007). The effectiveness of a suggested phonics-based program in developing some English reading readiness skills among primary pupils. Unpublished master thesis, Faculty of Education, Mansoura University

Fritschmann, N., Deshler, D., \& Schumaker, J. (2007). The effects of instruction in an inference strategy on the reading comprehension skills of adolescents with disabilities. Learning Disability Quarterly, 30, 4, 245-262. Retrieved May 29, 2013, from www.jstor.org/stable/25474637

Gersten, R., Fuchs, L., Williams, J., \& Baker, S. (2001). Teaching reading comprehension strategies to students with learning disabilities: a review of research. Review of Educational Research, $71,2,279-320$.

Ghanem, I. (2001). Effectiveness of metacognitive strategy training for developing EFL students reading comprehension. Unpublished master thesis, Faculty of Education, Tanta University

Gilani, M., Ismail, H., \& Gilakjani, A. (2012). Impacts of learning reading strategy on students' reading comprehension proficiency. The International Journal of Language Learning and Applied LinguisticsWorld, 1, 1, 72-87. 
Gunning, T. (2010). Assessing and correcting reading and writing difficulties. Boston: Pearson.

Guthrie, J., \& Wigfield, A. (2000). Engagement and motivation in reading Handbook for Reading Research, 3, 403-433.

Hagaman, J., \& Reid, R. (2008). The effect of the paraphrasing strategy on the reading comprehension of middle school students at risk of failure in reading. Remedial and Special Education, 29, 4, 222234.

Khalil, S. (2012). The effect of metacognitive strategy awareness on EFL acquisition on adults. Unpublished master thesis, Faculty of Arts. Helwan University

Learning Strategies Guide. (2009). Retrieved February 11, 2013, from Center for Research on Learning: http://kucrl.org/sim/strategies.shtml

Lebzelter, S., \& Nowacek, E. (1999). Reading strategies for secondary students with mild disabilities. Intervention in School and Clinic, 34, 4, 212-219. Retrieved May 29, 2012, from http://isc.sagepub.com/content/34/4/212

Lencioni, G. (2013). The effects of explicit reading strategy instruction and cooperative learning on reading comprehension in fourth grade students. Unpublished doctoral dissertation, Faculty of Education. University of San Francisco

Lenz, B. (2006). Planning a school-wide approach to promoting adolescent literacy. Boston: The University of Kansas Center for Research on Learning.

Luke, S. (2006). The power of strategy instruction. Evidence for Education, 1, 1. Retrieved April 15, 2013 from http://nichcy.org/research/ee/learning-strategies

Maasum, T., \& Maarof, N. (2012). Empowering esl readers with metacognitive reading strategies. Procedia Social and Behavioral Sciences, 69, 1250-1258. 
McEwan, E. (2001). Raising reading achievement in middle and high school: 5 simple to follow strategies for principals. California: Crown Press.

McLaughlin, M. \& Allen, M. (2002). Guided Comprehension: A teaching model for grades 3-8. Newark, DE.

McTavish, M. (2008). "What were you thinking?" the use of metacognitive strategy during engagement with reading narrative and informational genres. Canadian Journal of Education, 31,2, 405- 430. Retrieved September 23, 2012, from http://www.jstor.org/stab

Mehrdad, A., Ahghar, M., \& Ahghar, M. (2012). The effect of teaching cognitive and metacognitive strategies on EFL students' reading comprehension across proficiency levels. Procedia Social Behavioral Sciences, 46, 3757-3763.

Mokhtari, K., \& Reichard, C. (2004). Investigating the strategic reading processes of first and second language readers in two different cultural contexts. System, 32, 379-394. Retrieved from www.elsevier.com/locate/system

Mokhtari, K., \& Reichard, C. (2002). Assessing students' metacognitive awareness of reading strategies. Journal of Educational Psychology, 94 ,2, 249-259.

Moussa, F. (1984). Test of mental ability (12-14 years). Cairo: AngloEgyptian

Perfetti, C., Linda, N., \& Oakhill, J. (2005). The acquisition of reading comprehension skill. In M. J. Snowling \& C. Hulme (Eds.)The science of reading: Ahandbook. Oxford: Blackwell.

Peterson, C., Caverly, D., Nicholson, S., \& Cusenbary, S. (2000). A guide to building reading proficiency at the secondary level. Southwest Texas: Southwset Educational Development Laboratory. 
Pressley, M. (2000). What should the comprehension instruction be the instruction of? Handbook of Reading Research, 3, pp.545-651.

Reid, G. (2005). Dyslexia. Cornwall: Continum International Publishing Group.

Reid, R., \& Lienemann, T. (2006). Strategy instruction for students with learning disabilities. New York: Guilford Publications.

Saskatchewan. (2004). Teaching Students with reading difficulties and disabilities: a guide for educators. Saskatchewan University. Retrieved December 15, 2012, from www.education.gov.sk.ca/reading-difficulties-disabilities

Schumaker, J., \& Deshler, D. (2006). Teaching adolescents with disabilities: Accessing the general education curriculum. New York: Crowin Press.

Schumaker, J., Deshler, D., Zemitzsch, A., \& Warner, M. (1993). The visual imagery strategy. Lawrence, KS: The University of Kansas.

Strategic Instruction Model Guide. (2011, December). Retrieved June 12, 2013, from Center for Research on Learning: http://www.kucrl.org/sim/index.shtml

Swanson, H., \& Deshler, D. (2003). Instructing adolescents with learning disabilities: covering a meta-analysis to practice. Journal of leraning disabilities, 36, 2, pp. 124-135.

Temur, T., Kargin, T., Bayar, S., \& Bayar, V. (2010). Metacognitive awareness of grade 6,7 and 8 students in reading process. Procedia social and Behavioral Sciences, 2, 4193-4199.

Trainin, G., \& Swanson, S. (2005). Cognition, metacognition, and achievement of colleges students with learning disabilities. Learning Disability Quarterly, 28, 4, pp. 261-272. 
Watson, S., Gable, R., Gear, S., \& Hughes, K. (2012). Evidence-based strategies for improving the reading comprehension of secondary students: implications for students with learning disabilities. Learning Disabilities Research \& Practice, 27, 2, 79-89.

Yasin, W. (2002). The effectiveness of the language experience approach on developing some reading skills of preparatory stage pupils in the reader. Unpublished master thesis. Faculty of Education, Mansoura University.

Zaza, M. (2001). Developing metacognitive strategies and determining their effect on the academic reading skills freshmen students of the English section in faculties of education. Unpublished master thesis, Faculty of Education, Banha University

Zoghi, M., Mustapha, R., \& Maasum, T. (2010). Looking into efl reading comprehension. Procedia Social and behavioral Sciences, $7(\mathrm{c}), 439-445$. 